\title{
Influence of GGBS- based Geopolymer Aggregate on Compressive Strength of Concrete
}

\author{
Mrs. Jayadurgalakshmi.M¹, Mr. Udhaya Kumar. T², Mr. Selvendran. $\mathbf{E}^{3}$ \\ ${ }^{1,2,3}$ Assistant Professor, Department of Civil Engineering, Vel Tech, Chennai -62.
}

Article History: Received: 10 November 2020; Revised: 12 January 2021; Accepted: 27 January 2021; Published online: 05 April 2021

\begin{abstract}
Concrete is the most widely used building component in the world due to its versatility, low cost and durability. Most common coarse aggregate used in the construction are stones which is obtained from quarry. The demand for coarse aggregate in the construction industry has consequently increased due to the extensive use of natural resources. It has necessitated research into alternative materials of construction. This research aims to find the alternate material for coarse aggregate by using Ground Granulated Blast furnace Slag (GGBS) clinker and to determine the hardened properties of non-conventional concrete in M20 Grade. The aggregate utilized in this work is an Eco friendly material, which replace the conventional coarse aggregate to preserve the depletion of natural resources. It is abundantly available than the conventional aggregate and reduce pollution. This paper focuses on investigating characteristics of concrete with replacement of coarse aggregate by GGBS Clinker. This study deals with the GGBS clinker advantages and limitations in concrete. The usage of GGBS clinker serves as a replacement of conventional aggregate to reduce the depletion of conventional building materials. It serves as an Eco friendly way of utilizing the by- product without dumping it on ground.
\end{abstract}

Keywords: GGBS clinker, Durability, Eco friendly, Conventional aggregate.

\section{Introduction}

Concrete is one amongst the foremost wide used construction material, it's typically related to Portland cement because the main part for producing concrete. Ordinary Portland cement (OPC) is conventionally used because the primary binder to conventional concrete. Aggregate may be a broad class of coarse to medium grained particulate material employed in construction, as well as sand, gravel, crushed stone, slag, recycled concrete and geo artificial aggregates. These measure the foremost strip-mined materials within the world. In concrete, associate in concrete aggregate is employed for its economy issue, to cut back any cracks and most significantly to supply strength to the structure. Concrete is liable for strength, hardness and durability of concrete. Each fine and coarse aggregates, take concerning $65-75 \%$ by volume of concrete and it measure vital ingredients in concrete production. They will be classified as natural or artificial betting on their sources. Natural aggregates measure obtained from quarries by process crushed rocks or from riverbeds whereas artificial aggregates concrete measure obtained from industrial by product like furnace.

Concrete continues to be the foremost consumed construction material within the world, solely next to water. This truth is because of its appealing properties of high compressive strength and also the property of mouldability to any conceivable form. Because of high demand for construction activities in recent years in India and every one over the planet, the natural aggregates resources measure remarkably waning day by day. Natural resources are measure dwindling day by day because of their intensive use to deal with the increasing demand of civil engineering projects.

Developmental activities consume great amount of Precious natural resources. This ends up in quicker depletion of natural resources on one facet and manifold increase within the price of construction of structures on the opposite facet create severe downside for the construction sector. This downside is incredibly severe in developing countries like India.

In view of this, individuals have started looking for appropriate alternative viable various materials that might be used either as additive or as a partial replacement to the traditional ingredients of concrete so the prevailing natural resources might be saved to the potential extent, and will be created offered for the longer term generation. During this method, completely different industrial waste materials like fly ash, blast furnace slag, quarry dust, tile waste, brick bats, broken glass waste, waste aggregate from demolition of structures, ceramic material waste, etc. are tried as a viable substitute material to the traditional materials in concrete and has also been succeeded.

It is attempting to use Ground-granulated blast-furnace slag (GGBS) as an alternate material for coarse aggregate. GGBS is obtained by quenching molten iron slag as a by-product of iron and steel. It is making from a furnace in water or steam to supply a glassy and granular product that is dried and grinded into a fine powder.

\section{Material Properties}


This chapter presents the data regarding the constituents of GGBS aggregate and its application. Some essential literatures are reviewed to own a broad idea regarding GGBS aggregate.

\section{Ground Granulated Blast Furnace Slag (GGBS)}

Ground Granulated Blast Furnace Slag has been used as another binder. When activated by alkali $(\mathrm{NaOH}$, $\mathrm{Na}_{2} \mathrm{SiO}_{3}, \mathrm{KOH}$, etc.) solutions, slag dissolves and forms C-S-H the same as that found in OPC-based concretes. However, because of the presence of metallic element in dross, that prefers to make $\mathrm{C}-\mathrm{S}-\mathrm{H}$ because the primary strength bearing alkalinity.

Blast Furnace slag (BFS) could be a by-product of the ore refinement method. whereas all ore purification processes produce a 'slag' of one kind or another (e.g., copper slag, gold slag) the term is usually wont to talk to the by-product of iron production [6]. As the ore is melted, varied agents area unit another to delay impurities; they produce a non-metallic liquid composed in the main of silicates and alumino silicates of metallic element and alternative alkalis. The rapid quenching in water of the liquid slag, that floats at prime of the liquid iron, ends up in amorphous structure that may then be ground and used as a replacement for OPC because of its latent hydraulic properties (Environmental Protection Agency, 2010). After grinding, the resulting material is said as Ground coarse furnace dross, or GGBFS. Air cooled slag may also be used as aggregate in concretes, road bases, and alternative applications, however the crystalline structure of cool dross primarily nullifies reactivity. Value of each GGBFS and air cooled slag typically competitive with their counterparts (OPC and natural combination, respectively) despite the additional prices of grinding and transport.

\section{Alkaline Activator}

Activation of the chosen supply material is that the most important factor about manufacturing a mechanically-sound building material via the geo-polymerization method. The activators prompt the precipitation and crystallization of the silicious and aluminous species present in the solution. $\mathrm{OH}$ - particle acts as a catalyst for reactivity, and also the metal ion serves to make a structural part and balance the negative framework carried by the tetrahedral aluminium. The initial mechanism of reaction is driven by the power of the alkaline solution to dissolve the source material and release reactive solution and aluminium into solution. Fly ash or alternative source material is mixed with alkaline solutions, their vitreous element is quickly dissolved.

There is not sufficient time or space for the resulting gel to grow into a well crystallized structure. The subsequent could be a classification of varied teams of activating agents wherever $\mathrm{M}$ represents in alkali particle [5]:

- Alkalis, $\mathrm{MOH}$

- Weak acid salts, $\mathrm{M}_{2} \mathrm{CO}_{3}, \mathrm{M}_{2} \mathrm{SO}_{3}, \mathrm{M}_{3} \mathrm{PO}_{4}, \mathrm{MF}$

- Silicates, $\mathrm{M}_{2} \mathrm{O} * \mathrm{nSiO}_{3}$

- Aluminates, $\mathrm{M}_{2} \mathrm{O} * \mathrm{nAlO}_{3}$

- Alumino silicates, $\mathrm{M}_{2} \mathrm{O} * \mathrm{nAl}_{2} \mathrm{SO}_{3} * \mathrm{SiO}_{2}$

- Strong Salt Acids, $\mathrm{M}_{2} \mathrm{SO}_{4}$

While common activators embrace $\mathrm{NaOH}, \mathrm{Na}_{2} \mathrm{SO}_{4}$, sodium silicate, $\mathrm{Na}_{2} \mathrm{CO}_{3}, \mathrm{~K}_{2} \mathrm{CO}_{3}, \mathrm{KOH}, \mathrm{K}_{2} \mathrm{SO}_{4}$ and cement clinker, the foremost used alkaline activators area unit a combination of metal or metallic element hydroxides $(\mathrm{NaOH}, \mathrm{KOH})$ and metal sodium silicate $\left(\mathrm{nSiO}_{2} \mathrm{Na}_{2} \mathrm{O}\right)$ or metallic element sodium silicate $\left(\mathrm{nSiO}_{2} \mathrm{~K}_{2} \mathrm{O}\right)$.

\section{Sodium Hydroxide (NaOH)}

$\mathrm{NaOH}$ is additionally unremarkably used as alkaline activaor in geo-polymer production. whereas it doesn't maintain the extent of activation as a $\mathrm{K}+$ particle, metal cations area unit smaller than metallic element cations and may migrate throughout the paste network with a lot of less effort promoting higher zeolitization. what is more, it bears a high charge density that promotes extra zeolitic formation energy. The concentration and $M$ of this activating resolution determines the ensuing paste properties whereas high $\mathrm{NaOH}$ additions accelerate chemical dissolution, it depresses ettringite and $\mathrm{CH}$ (carbon-hydrogen) formation throughout binder formation. what is more, higher concentrations of $\mathrm{NaOH}$ promote higher strengths at early stages of reaction, however the strength of aged materials were compromised because of excessive $\mathrm{OH}$ - particle resolution inflicting undesirable moralkalinityology and non-uniformity of the ultimate product. It is found that geo-polymers activated with sodium hydroxide develop bigger crystallinity therefore rising stability in aggressive environments of sulalkalinityates and acids. To boot, the utilization of sodium hydroxide as activator buffers the hydrogen ion 
concentration of pore fluids, regulates association activity and directly affects the formation of the most C-S-H product in geo-polymer pastes. there's a linear relationship between $\mathrm{NaOH}$ concentration and also the heat generation; but, there exists inverse relationship between concentration and also the time at that most association heat happens. Duchesne(2010) confirmed that in presence of $\mathrm{NaOH}$ within the activating resolution, the reaction payoff quicker and also the gel is a smaller amount sleek. The gel composition analyzed within the sample activated with the aggregate of glass and metal $\mathrm{OH}$ is enriched in $\mathrm{Na}$ and $\mathrm{Al}$.

\section{Potassium Hydroxide (KOH)}

Potassium Hydroxide has been found to supply high compressive strengths and improved consistency in geo-polymer cements. Since $\mathrm{K}+$ is additional basic than alternative activating ions, it possesses a bigger potential for compound ionization in resolution leading to high reactivity of the prime pozzolano, a denser final product and a matrix formation capable of achieving raised compressive strength values. However, $\mathrm{KOH}$ concentrations higher than ten $\mathrm{M}$ are shown to decrease strength because of excessive $\mathrm{K}+$ ions in resolution and $\mathrm{Si} / \mathrm{Al}$ activity of $\mathrm{KOH}$ primarily based cements occurred over those derived from $\mathrm{NaOH}$ activation. whereas $\mathrm{KOH}$ is reasoned to supply a bigger extent of dissolution because of its higher level of alkalinity, $\mathrm{NaOH}$ truly possesses a bigger capability to liberate salt and chemical compound monomers [9].

\section{Sodium Silicate $\left(\mathrm{Na}_{2} \mathrm{SiO}_{3}\right)$}

Palomo et al (1999) over that the sort of activator plays a very important role within the polymerization chemical change chemical action\} process. Reactions occur at a high rate when the alkaline activator contains soluble silicate, either sodium or potassium silicate compared to the use of only alkaline hydroxides. The addition of sodium silicate solution to the sodium hydroxide solution because the basic activator increased the reaction between the source and the solution. The sodium silicate activator dissolves rapidly and begins to bond ash particles. Open porosity may be ascertained and is rapidly crammed with gel as shortly because the liquid part is ready to achieve the ash particles. The liquid part is very important as a fluid transport medium allowing the activator to achieve and react with the ash particles.

Sodium (or potassium) silicates area unit factory-made by fusing sand $\left(\mathrm{SiO}_{2}\right)$ with metal or carbonate $\left(\mathrm{Na}_{2} \mathrm{CO}_{3}\right.$ or $\mathrm{K}_{2} \mathrm{CO}_{3}$ ) at temperatures in more than $1100^{\circ} \mathrm{C}$ and dissolving the product with high steam into a semi-viscous liquid remarked as sodium silicate. Sodium silicate is never used as independent activating unit, as a result of it doesn't possess enough activation potential to initiate pozzolanic reaction alone. Rather, it's usually mixed with $\mathrm{NaOH}$ or $\mathrm{KOH}$ as a act aviating agent to boost alkalinity scale and increase overall specimen strength. the foremost common basic liquid utilized in geo-polymerization may be a combination of hydroxide or hydrated oxide and \{sodium salt soluble glass sodium silicate glass\} or potassium silicate.

Sodium silicate solution is commercially available in several grades, however it ought to be noted that pulverised sodium silicate ends up in lower performance compared to the liquid type. For best results, a salt resolution with a $\mathrm{SiO} 2$ to $\mathrm{Na} 2 \mathrm{O}$ magnitude relation (by mass) of 2.2 mixed with an 8-16 M activator a 24 hours before use is suggested. The foremost vital property of this product is its mass magnitude relation of $\mathrm{SiO}_{2}$ to $\mathrm{Na}_{2} \mathrm{O}$, that is commercially obtainable within the range of 1.5 to 3.2. Soluble silicates cut back alkali saturation in pore resolution and promote bigger lay particle bonding with each geo-polymer binders and therefore the enclosed aggregate material. Testing has unconcealed that activating solutions containing very little or no soluble silicates made considerably weaker compressive strengths of mortars and concretes than those activated with high doses of soluble silicates.

As well, the presence of such salt material improves surface bonding between rock aggregates and geo-polymer mortars. On the contrary, extra analysis shows that below increasing temperatures, specimens containing waterglass decrease in strength whereas those containing solely a base activator $(\mathrm{NaOH}, \mathrm{KOH})$ manufacture higher strengths. extra analysis remains needed to accurately confirm the precise effects made through the addition of solution into geo-polymer binder solutions [10].

\section{Literature Review}

\section{Non Conventional Aggregates}

Berger, R.L [11] has mentioned in his work that "concrete ready with unhydrated cement clinker substituted for the coarse or final natural aggregate showed improved compressive, flexural, and tensile strengths. Cement clinker hydration at some point before use as aggregate resulted in reduced concrete strengths. Expansion under water and 
shrinkage during a $50 \%$ relative humidity greater for concrete created with unhydrous cement clinker aggregate. Durability is around equal for non air entrained concrete created with either natural or unhydrous clinker aggregate".

Wahid Omar, et al [12] has worked on the behavior of pre stressed concrete beams made of clinker aggregate. The clinker is incorporated into the concrete as a right away replacement for each fine and coarse aggregates at 100 percent replacement level. The utilization of clinker light-weight concrete was found to save lots of the quantity of total load up to $18.8 \%$.

The check results show that the sunshine weight concrete using clinker exhibit associate degree nearly similar pattern in cracking behavior and failure modes. The study conjointly shows that clinker light-weight concrete exhibit smart performance and is appropriate to be utilized in prestressed concrete beam.

Monosi et al.[13] "The substitution of artificial aggregate in varieties of clinker grains for the natural aggregate, at equal particle size distribution exaggerated the compressive strength of Reactive Powder Concrete by concerning $20 \%$. The rise was solely $5 \%$ once the natural aggregate was a fine oxide powder and therefore the mortar aggregate was cured at aggressive $\left(160^{\circ} \mathrm{C}\right)$. The rise within the compressive strength of Reactive Powder Concrete containing clinker as coarse aggregate is attributable to a stronger bond between the cement matrix and therefore the clinker coarse aggregate particles as a result of surface chemical reaction".

Shen Yang et al.[14] "A terribly dense surface microstructure may be obtained in mortar containing corundum with hydraulic surface layer, just like the case in mortar containing cement clinker as aggregate. This causes filling-pore result and compacting action because of association of the hydraulic surface layer. For mortars containing inert aggregates, like quartz and corundum while not hydraulic surface layer, the surface zones arc abundant less dense than the corresponding bulk pastes".

\section{Summary of Literature}

GGBS primarily based concrete had wonderful compressive strength, suffer little and drying shrinkage and it is appropriate for structural applications. Alkaline liquid that contain soluble silicates area unit established to extend the speed of association reaction compared to alkaline solutions that contained solely hydroxide.

Based on the studies conducted on strength characteristics of concrete created with utilizing waste materials, it had been found that the concrete made from waste ceramic tile aggregate made similar strength in compression, split tensile and flexure as standard concrete. The compressive strength of concrete cubes created with ceramic stuff and glass concrete were found to be $16 \%$ and $26.34 \%$ lesser severally than that of standard concrete. it had been conjointly found that the flexural strength and split tensile strength results were just like that of compression strength take a look at results. Hence, it will be seen that waste ceramic tiles will be used as associate alternate construction material to coarse aggregate in concrete. Besides economical and strength criteria, concrete made up of waste materials as aggregates, solves the disposal drawback of those waste materials.

Compressive strength of GGBS clinker concrete was established to be exaggerated with increase in share of replacement of cement with GGBS. Cement will be replaced by GGBS up to 100 percent, on the far side that quick setting was determined. The wet and hardened concrete properties of GCC area unit compared with the results obtained from concrete made mistreatment standard aggregates. GCC is tested for each static and dynamic need to fulfill the standards of concrete for construction. Quantity of water needed for association and natural process of cement in standard concrete won't be needed within the production of GCC. It needs water just for the preparation. This study can profit the users in reducing water, in reducing greenhouse gas emission and in conserving natural resources.

Modern researchers have found GGBS is as associate alternate to traditional hydraulic cement. The probabilities of production of coarse and fine aggregates mistreatment GGBS is tried here. The concrete made from GGBS clinkers can cut back each exploitation of natural resources and emission of greenhouse gas. GGBS clinker area unit made and so they are broken into items conventional to the particle sizes of CA and FA suggested by IS codes. Therefore made aggregates area unit used for the preparation of GGBS clinker.

\section{Methodology}


The methodology for the casting and testing of concrete beams by using standard aggregate and Non- standard aggregate (GGBS clinker) are described as follows: The physical properties of materials used were got wind as per relevant Indian Standards. Trial mixes were created and tested for compressive strength at seven days, fourteen days and twenty eight days. Proportions of the GGBS concrete aggregate summarized in Table 4.1. Alkaline resolution to GGBS was maintained as 0.55 . The concentration of hydrated oxide was maintained as $10 \mathrm{M}$. GGBS added by the replacement $100 \%$. The ambient curing condition was adopted for 28 days. Cement concrete and GGBS clinker aggregate concrete cubes of size $150 \mathrm{~mm}$ x $150 \mathrm{~mm}$ x $150 \mathrm{~mm}$ were casted for testing compressive strength at 7,14 and 28 days.

\section{Production of GGBS Clinker Aggregate}

- The GGBS cubes area unit crushed, sieved and picked up into the scale of $20 \mathrm{~mm}$ aggregates as mentioned in Figure 1. GGBS aggregates area unit needed to be conducted for aggregate crushing test according to IS $2386-$ Part-4

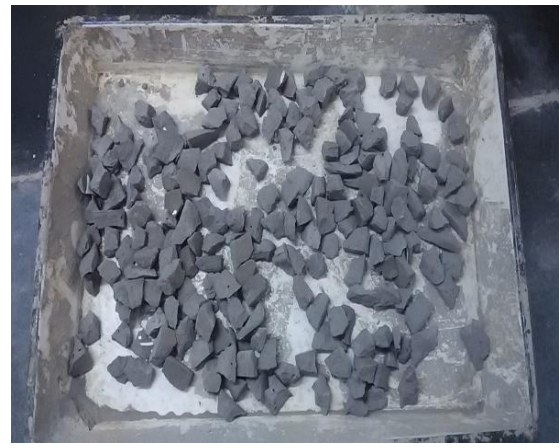

Figure 1. Crushed GGBS Clinker Aggregate

Table 1. Aggregate Proportion per $\mathrm{m}^{3}$ of GGBS Concrete

\begin{tabular}{|l|c|}
\hline Materials & Mass kg/m \\
\hline Alkaline solution / (GGBS) & 0.55 \\
\hline GGBS (100\%) & 450 \\
\hline Fine Aggregate & 564 \\
\hline Coarse Aggregate & 1015 \\
\hline Sodium Hydroxide solution & 70.85 \\
\hline Sodium Silicate Solution & 177.14 \\
\hline
\end{tabular}

\section{Results and Discussion}

In this chapter, the experimental results obtained are discussed in detail. GGBS clinker concrete mortar of size $150 \mathrm{~mm} \times 150 \mathrm{~mm} \times 150 \mathrm{~mm}$ were casted for testing aggregate crushing strength at twenty eight days. The GGBS clinker mixes was cast within the cube moulds and compacted. Specimens were demoulded when 24 hours. When demoulding, the specimens were cured by close condition. The GGBS clinker cubes area unit crushed, sieved and picked up into the scale of $20 \mathrm{~mm}$ aggregates. Geopolymer aggregate area required to be conducted for aggregate crushing test, Impact test, Specific gravity test and Water absorption test.

\section{Compressive Strength}

- Compressive strength of GGBS clinker concrete and cement concrete cubes was tested at twenty eight days more matured when casting on normal compression testing machine of $1500 \mathrm{kN}$ capacity, as per IS: 516-1959. Each of the compressive strength test knowledge corresponds to the norm of the compressive strength of three test concrete cubes. The average compressive strength for the GGBS Clinker concrete and OPC specimens were 28.24 $\mathrm{MPa}$ and 24.1 MPa at 28-days respectively.

- From the results, the mineral composition of GGBS Clinker contributes to the present shrinkage resistance. It is seen GGBS clinker aggregate may be a smart replacement to natural coarse aggregate and serves effectively by substitution the coarse aggregate. It provides superb results at later strength and a greener approach in construction and sustainable development that which we engineers are dependent on nowadays.

\section{References}


1. Bhikshma.V, Kotireddy.M and Srinivasarao.T, (2012), "An experimental investigation on properties of geo-polymer concrete (no cement concrete)", Department of Civil Engineering, University College of Engineering, Osmania University, Hyderabad, India, Asian Journal of Civil Engineering (Building and Housing) Vol. 13, no. 6, pp 841-853

2. Brooke, (2005), “Application of geo-polymer concrete to structural members", Department of Civil \& Construction Engineering, Curtin University of Technology.

3. Cheng T.W., Chiu J.P., (2003), 'Fire-resistant geo-polymer produced by granulated blast furnace slag' Department of Materials and Mineral Resources Engineering, National Taipei University of Technology, Taipei 106, Taiwan, ROC, Minerals Engineering 16, 205-210.

4. Chindaprasirt.P, Chareerat.T, Sirivivatnanon.V, (2006), "Workability and strength of coarse high calcium geo-polymer" KhoenKaen University, 224-229.

5. Dattatreya. J.K, Rajamane NP (2011) 'Flexural Behaviour of reinforced geopolymer concrete beams", CSIR,Taramani,chennai,.

6. Dattatreya JK, Sabitha.D, Lakshmanan.N, (2012), "Sustainability acid resistant ecofriendly concrete from geo-polymerization of blast furnace slag' CSIR - Structural Engineering Resaearch Center, Chennai 600 113, India, Vol-19, ,pp. 357-367.

7. Davidovits, J, (1994), "High-Alkali Cements for 21st Century Concretes. in Concrete Technology, Past, Present and Future", Proceedings of V. Mohan Malhotra Symposium, Editor: P. KumarMetha, ACI SP- 144, pp.383-397.

8. Duxson P, Provis J L, Lukey G C and van Deventer J S J, (2007). "The Role of Inorganic Polymer Technology in the Development of Green Concrete", Cement and ConcreteResearch, 37(12), pp. 1590-1597

9. DjwantoroHardjito, Chua Chung Cheak\& Carrie Ho Lee Ing, (July 2008), Department of Civil \& Construction Engineering, Curtin University of Technology, 98009, Miri, Sarawak, Malaysia, Vol. 2, No. 4.

10.DjwantoroHardjito, Steenie E. Wallah, and Dody M.J., Sumajouw, "Studies on fly ash-based geo-polymer concrete", Faculty of engineering, Curtin university of technology, Australia, pp 133-138.

11.Hardijito and Rangan, (2010) "Development and properties of low calcium fly ash-based on geo-polymer concrete", International Journal of the Alkalinityysical Sciences, Vol.5(9), pp 1419-1423.

12. Harris, A. S., (1969) "High StrengthConcrete: Manufacture and Properties," The Structural Engineer, 47, II, p. 441.

13.LawsonI., DansoK.A., OdoiH.C., (2011), "Non-Destructive Evaluation of Concrete using Ultrasonic Pulse Velocity" Nuclear Applications Centre (NAC), Ghana.

14. Mangat S and Mahmoud S. Elgarf, (January-February 1999) "Flexural strength of concrete beams with corroding reinforcement", ACI Structural Journal.

15. Manjunath.G. Radhakrishna S, Giridhar.C, Mahesh Jadhav, (2011) "Compressive strength development in ambient cured geo-polymer mortar", International Journal of Earth Sciences and Engineering,ISSN 0974-5904, Volume 04, No 06 , , pp. 830-834.

16. McCaffrey, R., (2002), "Climate Change and the CementIndustry", Global Cement and Lime Magazine (EnvironmentalSpecial Issue), pp. 15-19. 